\title{
INNOVATION AND RE-ORIENTATION IN MEDICAL EDUCATION AND RESEARCH: CHALLENGES FOR IBRAHIM MEDICAL COLLEGE
}

Medical Education in Bangladesh is still predominantly in the public sector, controlled by the Ministry of Health \& Family Welfare; regional public Universities conduct examinations and confer degrees; while Bangladesh Medical \& Dental Council (BM\&DC) oversee the standard and equivalence. Medical education under the rule of the triumvirate the Ministry, the University and the BM\&DC has developed without a progressive plan to keep pace with exponential growth of medical knowledge and technology on one hand and ever growing health needs of the people on the other.

The 'Undergraduate Medical Curriculum' first made available in the written form in $1982^{1}$ and updated in $2002^{2}$ still remained largely disease and treatment oriented rather than emphasizing prevention of the diseases and promotion of health. It is still a blend of traditional with sporadic inclusion of modern advances. The new additions without concomitant removal of the old and outdated have made the curriculum lengthy and at places boring. Priorities in selecting topics reflected more of faculties' choice of academic interest and of recent advances rather than national perspectives that emphasizes diseases with greater potential for harm to public health, diseases that are preventable and focus for national disease control programmes.

The teaching strategies largely remained didactic, teacher centered, lecture dominated and examination oriented and is devoid of motivation for self and continuous learning. The teaching-learning activities in basic science departments have been criticized for their lack of clinical relevance, while those in clinical departments for their undue stress on diseases and their treatment at the tertiary level rather than symptoms oriented approach for early diagnosis; dependence on laboratory investigation rather than development of clinical acumen through elicitation of history and thorough clinical examination; and use of hospital inpatients rather than outpatients and community settings ${ }^{3}$.

Private initiatives in the establishment of medical colleges started with the promise of a competition for better future. However rapid establishment of quite a number of private medical colleges over a short period has generated considerable concern, for acute dearth of qualified teachers particularly in basic science departments and non-availability of adequate hospital beds for teaching may have adverse effects on the quality of education and training provided.

It is in this background, the Diabetic Association of Bangladesh established Ibrahim Medical College after the name of its founder National Prof. Md. Ibrahim with a vision to develop it as a trend-setting Institute, so as to demonstrate a high standard of undergraduate medical education, so badly needed in the country. The college is committed to provide an environment conducive to innovation and re-orientation in medical education and research appropriate to the need of the country while at the same-time remaining at par with world standard.

The goal of the college is to create future leaders of the profession who will be competent, caring and willing to serve the community. The college is to provide a broad based education through a well designed curriculum that stresses the national perspective; utilizing effective educational strategies to encourage self learning; and continuously monitoring and rigorously evaluating all activities and systems.

Medicine is a science with a human understanding and warmth; and embraces man, his environment and society. Medical Colleges have an obligation to the society to direct its education, services and research towards addressing the priority health concerns of the community they have a mandate to serve ${ }^{4}$. The focus therefore is on professional development for the students to equip them with knowledge, skill and attitude necessary not only to address the priority health problems of the community; but also to acquire a firm basis for future training and studies; to develop a capacity for self-education so that he may continue to extend his knowledge and skill throughout his professional life; and to recognize his obligation to contribute if he can, to the progress of medicine and to new knowledge.

Following the recommendations of the World Congress of Medical Education ${ }^{5}$, the college is committed to enlarge the range of settings in which educational programmes are conducted to include all health resources of the community and not hospitals alone. It is implementing a comprehensive approach to conduct 
community related educational programmes and services throughout undergraduate education and during internship and to conduct operational research on community health problems.

The College provides the right academic environment for faculty development. Fellowship, travel grants and exchange programmes for teachers have been planned to give teachers access to outside academic world. There are opportunities for young doctors in teaching for career development with provisions for scholarships and study leave.

The college attaches highest priority and encourages ways and means to promote research activities in the college. Research is considered as yardstick for measuring excellence of an academic institution. Education confined to text books and repetition of the same dull chores round the year do not stimulate true learning. Through research, teachers can communicate with rest of the scientific world, remove academic isolation, bring innovative changes in teaching strategies and add to the prestige of the Institution and of the country. The publication of "Ibrahim Medical College Journal" is a step in that direction and a great leap forward towards a highly productive academic pursuit. We wish the publication a continued success.

Prof. A.K.M. Nurul Anwar

Principal, Ibrahim Medical College

Prof. K.M. Fariduddin

Adviser, Ibrahim Medical College

\section{References:}

1. Centre for Medical Education, DGHS: Curriculum for Undergraduate Medical Education in Bangladesh, 1988.

2. Centre for Medical Education, DGHS: Curriculum for Undergraduate Medical Education in Bangladesh approved by BM\&DC, 2002.

3. Anwar, AKMN. Editorial: Medical Education for Bangladesh in the New Millennium. Bangladesh J. Physiol \& Pharmacol 2002; 16(2): 47-49.

4. General Medical Council; Tomorrows' Doctors: Recommendations on Undergraduate Medical Education, June 2003.

5. Proceedings of the World Congress of Medical Education, Edinburgh 1990. 